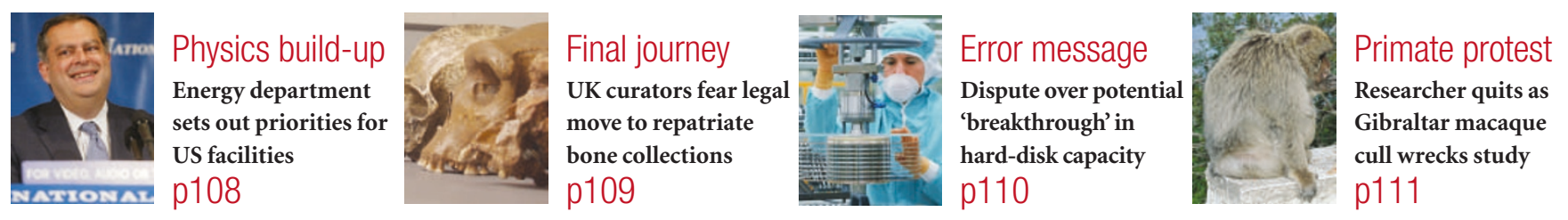

\title{
Consumers warned that time is not yet ripe for nutrition profiling
}

\section{Erika Check}

One day, information about your genome may well help you decide what breakfast cereal to eat. But that day's a long way off, the second International Nutrigenomics Conference in Amsterdam was told last week. In the meantime, researchers at the meeting heard, the emerging field badly needs a regulatory framework that will stop its first customers from being scared off.

Nutrigenomics researchers aim to learn how nutrients interact with genes to lead to health or disease. But people eat wildly different levels of nutrients over their lifetimes, and teasing apart the precise interactions is notoriously difficult.

The researchers who gathered in Amsterdam on 6-7 November were in optimistic mood, however. Their science is progressing quickly, and food industry executives have expressed interest in the idea of using genetic information to customize their products.

In January, the US National Institutes of Health used a 5-year, \$6.5-million grant to create a National Center of Excellence for Nutritional Genomics at the University of California, Davis, and the Children's Hospital Oakland Research Institute (CHORI) in Oakland. In July, the European Commission set up the European NutriGenomics Organisation to coordinate work. Now the Netherlands looks set to embark on a \$20-million nutrigenomics project, jointly funded by the government and the food industry.

But some researchers warn that the field is in danger of developing too quickly. They want experts to back off from the sometimes-extravagant claims for the field's potential, and instead to sit down and patiently work out a scientific vision and ethical framework for the discipline.

"Our aim is to bring the field a little bit back down to Earth, because people tend to start with a lot of science fiction," says Michael Müller, a genomicist at Wageningen University in the Netherlands who helped to organize the meeting.

The main fruits of this field are still years away, researchers say. So far, most of the studies on profiling gene expression - measuring genome-wide responses to nutrients -

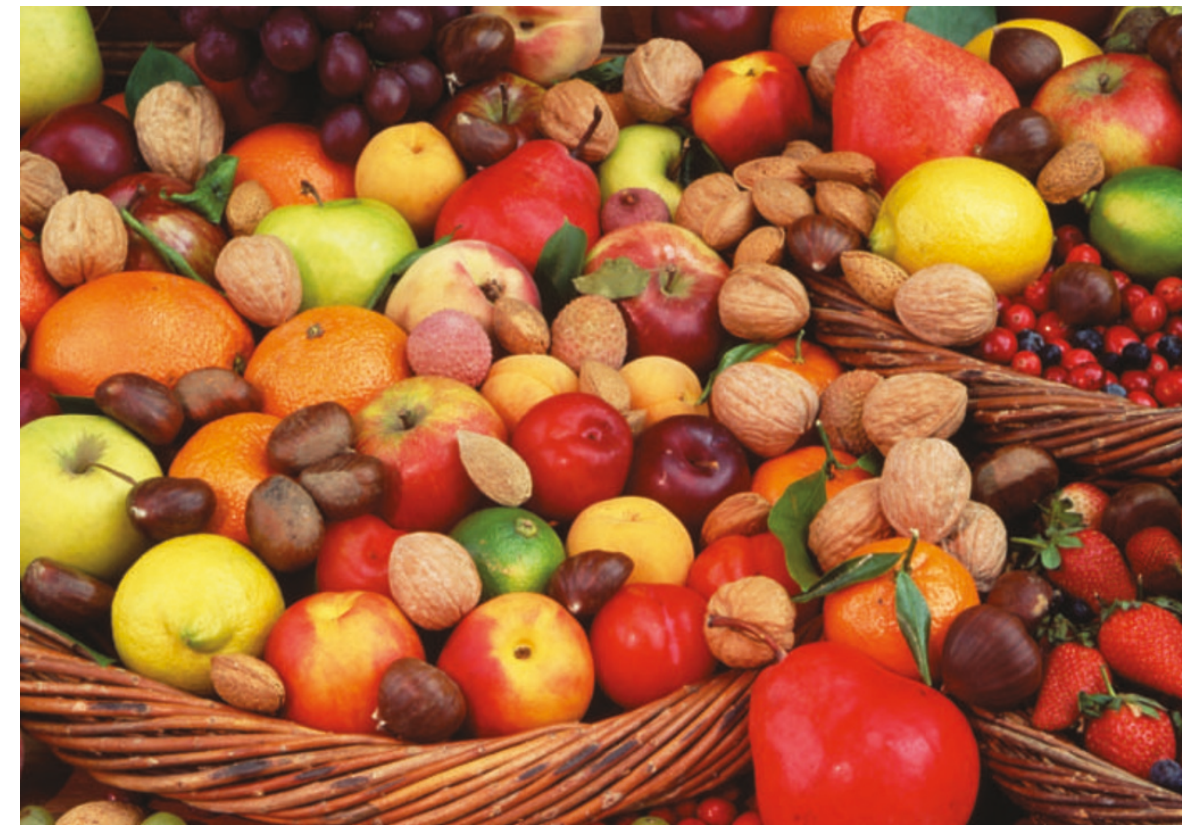

Looks good, tastes good, and one day individuals may know exactly how much good it does them.

have been done in mice. And much more work is needed on the basic mechanisms by which nutrients turn genes on or off. But that hasn't stopped a handful of companies from selling nutritional profiles directly to consumers over the Internet.

The companies test a tissue sample such as a cheek swab - from a "patient". The patient can choose which genetic profile he or she wants to learn about, for example skin ageing or susceptibility to osteoporosis. The company then gives the patient a "personalized profile" based on its tests for single nucleotide polymorphisms (SNPs): genetic variants that have been linked to disease. For instance, one company, GeneLink of Margate, New Jersey, tells people what vitamins they should take, based on SNPs involved in cellular responses to certain toxins. GeneLink declined to comment on its products.

But many scientists argue that it's far too early for most of these tests to be useful. "The idea of marketing any individual genetic test at this point assumes there is information to justify the use of that test, and we really don't have evidence that any single genetic marker carries enough information to guide dietary treatments," says Ronald Krauss, director of atherosclerosis research at CHORI.

The direct-to-consumer tests also raise ethical issues that affect the whole field. For instance, some companies sell the results of their genetic profiles to other firms, which use the information for research on genes and disease. Although consumers must give their consent, they may not necessarily understand what they're agreeing to, says ethicist David Castle of the University of Guelph. Castle is collaborating with the University of Toronto Joint Center for Bioethics in soliciting comments on a joint working paper on ethics and nutrigenomics.

At the nutrigenomics meeting, Castle argued that even though the field is very young, scientists must begin talking to the public about such issues.

"This technology could end up affecting something that every person does every day, which is eat," Castle says. "It's not a situation where you want to roll out the science and the products and then go back and ask people how they feel about it." 